\title{
AISLAMIENTO DE MICROORGANISMOS A PARTIR DEL FLUIDO DIGESTIVO DE LARVAS DE Rhynchophorus palmarum (COLEOPTERA: CURCULIONIDAE)
}

\section{ISOLATION OF MICROORGANISMS FROM THE DIGESTIVE FLUID OF LARVAE OF Rhynchophorus palmarum (COLEOPTERA: CURCULIONIDAE)}

\author{
Marcos David Landívar Valverde ${ }^{1}$, David Sancho Aguilera ${ }^{1}$, Josselyn Paulina Pico Poma ${ }^{1}$, Diego Abelardo Sarabia \\ Guevara $^{1}$, Pamela Jacqueline Pintado Vallejo ${ }^{1}$
}

${ }^{1}$ Universidad Estatal Amazónica, Paso Lateral Km 2 1⁄2 Vía a Napo. Puyo, Pastaza - Ecuador

Email: md.landivarv@uea.edu.ec

\section{Información del articulo}

Tipo de artículo:

Nota Técnica

Recibido:

$01 / 10 / 2021$

Aceptado:

$28 / 12 / 2021$

Licencia:

CC BY-NC-SA 4.0

Revista ESPAMCIENCIA

12(2):152-157

DOI:

https://doi.org/10.5

1260/revista_espam

ciencia.v12i2.251

\section{Resumen}

Se tuvo como objetivo aislar bacterias, levaduras y un hongo ascomiceto, a partir del fluido digestivo de larvas de Rhynchophorus palmarum. Las larvas fueron adquiridas en mercados de productos típicos de la Amazonia. Los ejemplares se seleccionaron de acuerdo a su peso y talla aproximados, para luego ser disecados en condiciones de esterilidad y obtener una suspensión de fluido intestinal, que fue diluida y sembrada en medio sólido y líquido. Para el aislamiento microbiano, se consideraron aproximaciones para el cultivo de bacterias y hongos o levaduras, tanto en condiciones aeróbicas como anaeróbicas y microaerófilas. Las colonias aisladas se llevaron hasta cultivos puros, obteniéndose un total de catorce aislados, representados en su mayoría por bacilos Gram negativos y, en menor proporción por hongos y levaduras. En cuanto a su requerimiento de oxígeno, la mayoría de los aislados corresponde a microorganismos aeróbicos, con una escasa presencia de aislados anaeróbicos y microaerófilos.

Palabras clave: Larvas, aislamiento, microorganismos, Rhynchophorus, palmarum

\begin{abstract}
The objective was to isolate bacteria, yeasts and an ascomycete fungus from the digestive fluid of Rhynchophorus palmarum larvae. The larvae were acquired in typical product markets of the Amazon. The specimens were selected according to their approximate weight and size, to later be dissected under sterile conditions and obtain a suspension of intestinal fluid, which was diluted and sown in solid and liquid medium. For microbial isolation, approaches were considered for the culture of bacteria and fungi or yeasts, both under aerobic, anaerobic and microaerophilic conditions. The isolated colonies were brought up to pure cultures, obtaining a total of fourteen isolates, mostly represented by Gram negative bacilli and, to a lesser extent, by fungi and yeasts. Regarding their oxygen requirement, most of the isolates correspond to aerobic microorganisms, with a scarce presence of anaerobic and microaerophilic isolates.
\end{abstract}

Keywords: Larvae, isolation, microorganisms, Rhynchophorus, palmarum.

\section{INTRODUCCIÓN}

Los insectos representan la mayor biomasa del planeta, superando con creces a la del resto de formas de vida juntas (Capinera, 2010). Adicionalmente, los insectos desempeñan un rol clave en la descomposición de la biomasa lignocelulósica en los ecosistemas (Fischer et al., 2013).

Por otra parte, una de las claves para el éxito evolutivo de los insectos reside en la simbiosis con microorganismos, que proporcionan importantes beneficios, incluyendo la síntesis de sustancias esenciales $\mathrm{y}$, sobre todo, la 
degradación y asimilación de sustratos que sirven de alimento a los insectos (Engel y Moran, 2013). De hecho, se ha demostrado que muchas de las interacciones que ocurren entre microorganismos e insectos ocurre a nivel del tracto digestivo, a tal punto que se puede afirmar que la cantidad de microorganismos presentes en el tubo digestivo puede superar con creces a las propias células del insecto, al igual que ocurre en muchos organismos pluricelulares (Dillon y Dillon, 2004).

Por otra parte, la biomasa lignocelulósica va cobrando importancia como una alternativa sostenible y renovable para la producción energética, tanto en la producción de biocombustibles de cuarta generación, así como en la producción de biogás, biohidrógeno y en la producción de biopolímeros (Delidovich et al., 2016; Limayem y Ricke, 2012).

Los insectos que degradan la biomasa vegetal son capaces de convertir esta compleja amalgama de sustancias en energía para el sostenimiento de su metabolismo (Oppert et al., 2010). Esta capacidad es compartida por diferentes órdenes de insectos, que incluyen lepidópteros, himenópteros, isópteros y coleópteros (Szentner et al., 2019). Dentro de este proceso degradativo, la microbiota intestinal endosimbionte de los insectos desempeña un rol clave, pues se ha comprobado la presencia de hongos y bacterias que producen diferentes clases de enzimas involucradas en el proceso de degradación de la biomasa vegetal (Govindarajulu et al., 2020).

A nivel de los insectos, los coleópteros son quizá los más especializados en la descomposición de la biomasa lignocelulósica, requiriendo un cóctel enzimático muy complejo para tal efecto (Vatanparast et al., 2014). Por otra parte, en el Ecuador, uno de los coleópteros más conocidos es el Rhynchophorus palmarum, cuyas larvas son consumidas como alimento por los pobladores de la Amazonia, conocidas como "chontacuro", "mukinde" o "mayón” (Sancho et al., 2015).

Por otra parte, la información disponible deja entrever una compleja interacción entre la microbiota intestinal de los insectos comestibles, que tiende a crear complejos ecosistemas, con marcadas variaciones a nivel de cantidad y diversidad de especies encontradas (Garofalo et al., 2019). Adicionalmente, (Jang y Kikuchi, 2020), citan otros efectos de la microbiota intestinal sobre la fisiología de los insectos, que incluyen la degradación de sustancias tóxicas, e incluso la producción de ciertos compuestos antimicrobianos que permiten combatir parásitos y patógenos.

En cuanto a la naturaleza y composición de la microbiota intestinal de los insectos, Garofalo et al. (2019) describen que esta se halla principalmente constituida por aerobios mesófilos, que incluyen enterobacterias, bacterias acidolácticas, bacterias esporulantes e inclusive hongos. Pese a ello, la mayoría de los intestinos de insectos contienen relativamente pocas especies microbianas, a comparación de los mamíferos, por ejemplo. No obstante, los tractos digestivos de los insectos varían notablemente en forma y fisiología. Este hecho, sumado a la capacidad colonizadora de los microorganismos oportunistas, puede influenciar enormemente las características de la microbiota presente en los insectos.

En tal sentido, el estudio de la microbiota a nivel de los insectos fitófagos ha cobrado una importancia relevante en la última década, animado por el potencial que supone entender los efectos fisiológicos y ecológicos de la relación microorganismos-insectos, así como la perspectiva de usar a estos microorganismos como potenciales fuentes de enzimas que puedan emplearse en la degradación y sacarificación de la biomasa lignocelulósica (Jang y Kikuchi, 2020; Pal y Karmakar, 2018).

El objetivo de la investigación fue aislar bacterias, levaduras y un hongo ascomiceto, a partir del fluido digestivo de larvas de Rhynchophorus palmarum.

\section{MATERIALES Y MÉTODOS}

\section{Selección de las larvas y obtención del fluido intestinal}

Para este estudio se adquirieron un total de 150 larvas de Rhynchophorus palmarum, en los mercados locales de la ciudad de Francisco de Orellana, Ecuador. Las larvas fueron mantenidas en el sustrato natural de fibra de morete (Mauritia flexuosa) y trasladadas al laboratorio de Biología de la Universidad Estatal Amazónica, sede Puyo, para su posterior selección y disección.

La selección de las larvas se realizó según su peso y longitud aproximadas, coincidiendo con el octavo y noveno instares larvales descritos para $R$. palmarum (Delalibera et al., 2005). Los individuos muertos o con lesiones en sus tejidos fueron descartados, quedando un total de 120 ejemplares para estudio. Las larvas fueron mantenidas en contenedores plásticos con sustrato constituido por fibra de palma Bactris gasipaes.

Previo a la disección, las larvas fueron divididas en unidades experimentales, formadas por cinco ejemplares, que fueron colocados en vasos de precipitación de $1 \mathrm{~L}$ y luego sometidos a una temperatura de $4^{\circ} \mathrm{C} 15$ minutos, para inducir su inmovilización.

La desinfección se realizó por inmersión en etanol al 70\% durante 30 segundos, seguida de un doble lavado con agua destilada estéril. La disección se realizó en una cabina de flujo laminar Heraeus HS9 (Hanau, Alemania). 
Durante la disección, se practicó una incisión inicial en la parte anterior del tórax, alrededor de la cabeza de las larvas, seguida de un corte a lo largo del abdomen y terminado alrededor de la sección terminal del abdomen. Se separó cuidadosamente el tubo digestivo del resto del tejido abdominal y finalmente de la cabeza y el segmento anal.

Los tubos digestivos fueron colocados en viales de ensayo con $10 \mathrm{ml}$ de solución salina $\mathrm{NaCl}$ [0.9\%] estéril y agitados en vórtex durante dos minutos, para obtener una suspensión del fluido intestinal. Los viales fueron etiquetados y conservados a $4,0^{\circ} \mathrm{C}$.

\section{Aislamiento microbiano a partir del fluido intestinal}

Para el aislamiento microbiano se realizaró diluciones seriadas, de la suspensión intestinal, hasta un factor de $10^{-}$ 5. Para el aislamiento de bacterias se empleó medio Tripticasa de soya (Sigma-Aldrich), mientras que el aislamiento fúngico se realizó en medio Patata Dextrosa (Fluka). En ambos casos se consideraron medios agarizados (TSA/PDA) y no agarizados (TSB/PDB).

Se tomaron $100 \mu \mathrm{L}$ de suspensión intestinal y se sembraron por triplicado en cajas Petri plásticas y en frascos de cultivo Iwaki de $25 \mathrm{~cm}^{2}$ con tapa rosca, con 30 $\mathrm{ml}$ de medio agarizado y no agarizado, respectivamente. Se consideraron atmósferas de cultivo aeróbicas, anaeróbicas y microaerofílicas (Figura 1).

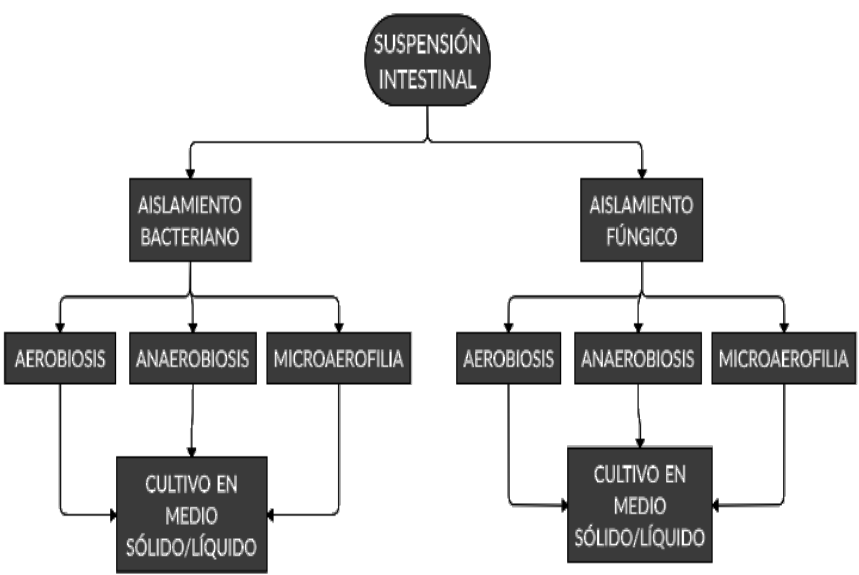

Figura 1. Esquema del aislamiento microbiano

Para cultivos en condiciones de anaerobiosis y microaerofilia se empleó jarras de incubación AnaeroJar AG0025 (Oxoid), con sistemas de generación de atmósfera AnaeroGen AN25US (Oxoid) y CampyGen CN025A (Oxoid), respectivamente. Se realizó pequeñas perforaciones en los bordes de las cajas Petri y se cerraron parcialmente las tapas de los frascos de cultivo celular, para facilitar la difusión de la atmósfera modificada. Para cultivos en atmósfera microaerófila, se consideró un porcentaje del $5 \%$ de $\mathrm{O}_{2}$ y menor al $1 \%$ de $\mathrm{O}_{2}$ para condiciones anaeróbicas.

Se sembraron dos muestras de suspensión intestinal, por cada unidad experimental, incubándose a una temperatura de $30^{\circ} \mathrm{C}$ durante 7 días, en una incubadora orbital SKI4 (Argolab), a 0 y $120 \mathrm{rpm}$ para cultivos en medio agarizado y no agarizado, respectivamente. Para el aislamiento microbiano se tuvo en cuenta características morfológicas de las colonias encontradas en las diversas condiciones de cultivo.

\section{RESULTADOS Y DISCUSIÓN}

\section{Aislamiento microbiano a partir del fluido intestinal}

Los microorganismos aislados fueron identificados según una codificación basada en el tipo microbiano y la atmósfera de cultivo en la que fueron aislados (Cuadro 1).

Cuadro 1. Codificación para aislados microbianos

\begin{tabular}{|c|c|c|c|c|}
\hline Origen & Categoría & Atmósfera & Serie & Ejemplo \\
\hline $\begin{array}{l}\text { Rhynchophorus } \\
\text { palmarum } \\
\text { (RP) }\end{array}$ & $\begin{array}{l}\text { Bacterias } \\
\text { (b) } \\
\text { Hongos (m) }\end{array}$ & $\begin{array}{c}\text { Aeróbico } \\
\text { (EC) } \\
\text { Microaerofílico } \\
\text { (ED) } \\
\text { Anaeróbico } \\
\text { (AN) }\end{array}$ & $\begin{array}{l}001 \\
002 \\
\text { etc. }\end{array}$ & $\begin{array}{l}\text { RPbEC-001 } \\
\text { RPbAN-001 } \\
\text { RPmED-001 } \\
\text { RPbED-001 } \\
\text { RPmEC-001 } \\
\text { RPmAN-001 }\end{array}$ \\
\hline
\end{tabular}

Con respecto a la concentración de oxígeno, en condiciones aeróbicas se identificó un total de ocho colonias, mientras que en condiciones de anaerobiosis y microaerofilia se obtuvo una sola colonia en ambos casos. Esta situación tiene relación con lo reportado por Engel y Morán (2013) quienes manifiestan que, pese a que el intestino de los insectos es anaeróbico por naturaleza, sigue siendo un ambiente propicio para el desarrollo de bacterias aeróbicas o facultativas, debido a la producción de catalasa que les permite generar oxígeno para su respiración. Esto coincide, además con el comportamiento reportado por Ramachandiran et al. (2018) para la microbiota bacteriana de Epilachna vigintioctopunctata (Coleóptera: Coccinellidae), donde el 50\% de los aislados bacterianos resultaron catalasa positivos.

En cuanto a hongos y levaduras, se obtuvieron cuatro colonias en total, de las cuales tres fueron aisladas en condiciones aeróbicas y una en condiciones microaerófilas. (Cuadro 2).

Cuadro 2. Descripción de los aislados microbianos 


\begin{tabular}{|c|c|c|c|}
\hline Aislado & Descripción & Tipo & Atmósfera \\
\hline RPbEC-001 & $\begin{array}{l}\text { Colonias } \\
\text { amarillentas, opcacas, } \\
\text { con bordes definidos } \\
\text { y crecimiento } \\
\text { ramificado }\end{array}$ & $\begin{array}{l}\text { Bacilo } \\
\text { Gram - }\end{array}$ & Aeróbica \\
\hline RPbEC-002 & $\begin{array}{l}\text { Colonias rojizas, } \\
\text { opacas, de bordes } \\
\text { lobulados y } \\
\text { crecimiento } \\
\text { ramificado }\end{array}$ & $\begin{array}{l}\text { Bacilo } \\
\text { Gram - }\end{array}$ & Aeróbica \\
\hline RPbEC-003 & $\begin{array}{l}\text { Colonias anaranjadas, } \\
\text { opacas y puntiformes }\end{array}$ & $\begin{array}{l}\text { Bacilo } \\
\text { Gram - }\end{array}$ & Aeróbica \\
\hline RPbEC-004 & $\begin{array}{l}\text { Colonias } \\
\text { amarillentas, opacas, } \\
\text { con bordes lobulados } \\
\text { y crecimiento } \\
\text { concéntrico }\end{array}$ & $\begin{array}{l}\text { Bacilo } \\
\text { Gram - }\end{array}$ & Aeróbica \\
\hline RPbEC-005 & $\begin{array}{l}\text { Colonias redondas, } \\
\text { opacas, blanquecinas } \\
\text { y con bordes lisos }\end{array}$ & $\begin{array}{l}\text { Bacilo } \\
\text { Gram + }\end{array}$ & Aeróbica \\
\hline RPbEC-006 & $\begin{array}{l}\text { Colonias } \\
\text { amarillentas, } \\
\text { traslúcidas de } \\
\text { crecimiento } \\
\text { concéntrico }\end{array}$ & $\begin{array}{c}\text { Bacilo } \\
\text { Gram + }\end{array}$ & Aeróbica \\
\hline RPbEC-007 & $\begin{array}{l}\text { Colonias redondas, } \\
\text { rojizas, opacas y } \\
\text { bordes definidos }\end{array}$ & $\begin{array}{l}\text { Bacilo } \\
\text { Gram - }\end{array}$ & Aeróbica \\
\hline RPbEC-008 & $\begin{array}{l}\text { Colonias } \\
\text { blanquecinas, con } \\
\text { bordes lobulados y } \\
\text { rodeadas de un halo } \\
\text { verdoso }\end{array}$ & $\begin{array}{l}\text { Bacilo } \\
\text { Gram - }\end{array}$ & Aeróbica \\
\hline RPbED-001 & $\begin{array}{l}\text { Colonias globulares } \\
\text { blanquecinas con } \\
\text { bordes lisos }\end{array}$ & $\begin{array}{l}\text { Bacilo } \\
\text { Gram - }\end{array}$ & Microaerófila \\
\hline RPbAN-001 & $\begin{array}{l}\text { Colonias amarillentas } \\
\text { traslúcidas con bordes } \\
\text { arrugados y } \\
\text { crecimiento } \\
\text { ramificado }\end{array}$ & $\begin{array}{l}\text { Bacilo } \\
\text { Gram - }\end{array}$ & Anaeróbica \\
\hline RPmEC-001 & $\begin{array}{l}\text { Moho ascomiceto } \\
\text { identificado como } \\
\text { parte de la familia } \\
\text { Ceratocystidaceae }\end{array}$ & Hongo & Aeróbica \\
\hline RPmEC-002 & $\begin{array}{l}\text { Colonias } \\
\text { blanquecinas, rígidas } \\
\text { y de aspecto } \\
\text { pulverulento }\end{array}$ & levadura & Aeróbica \\
\hline RPmEC-003 & $\begin{array}{l}\text { Colonias } \\
\text { amarillentas, rígidas y } \\
\text { de aspecto } \\
\text { pulverulento }\end{array}$ & Levadura & Aeróbica \\
\hline RPmED-001 & $\begin{array}{l}\text { Colonias } \\
\text { amarillentas, opacas } \\
\text { con bordes irregulares }\end{array}$ & Levadura & Microaerófila \\
\hline
\end{tabular}

El aislamiento de hongos en insectos y particularmente en los coleópteros ha sido reportado previamente en la literatura, pudiendo constituir los principales endosimbiontes fúngicos en ciertas especies, tal como lo reportan Samal y Kumar Sahu, (2020) para Sitophilus oryzae (Coleóptera: Curculionidae). Del mismo modo, existe evidencia suficiente para suponer que esta clase de hongos degradan y debilitan los tejidos vegetales, facilitando a los insectos el poder alimentarse de estos (Jacobsen et al., 2018).

En lo concerniente a la naturaleza de los aislados microbianos, la mayoría de estos corresponden a bacterias Gram negativas, lo cual ha sido observado de manera similar en otros insectos que se alimentan de la biomasa lignocelulósica, particularmente a nivel de la familia Curculionidae, tal como reportan Sufian et al. (2020).

La composición exacta de la microbiota larval de $R$. palmarum, no obstante, permanece sin conocerse; debido a las limitaciones que plantea el aislamiento microbiano por técnicas convencionales y a la necesidad de requerir forzosamente la identificación vía $\mathrm{ADN}$ de toda la comunidad microbiana, para estos casos. A pesar de ello, el protocolo de aislamiento microbiano se basó en la premisa que la microbiota intestinal de los insectos puede incluir microorganismos aeróbicos estrictos, facultativos, anaeróbios obligados y microaerófilos, así como hongos y levaduras.

Respecto a los requerimientos de oxígeno de los aislados microbianos, se determinó que la mayoría de estos corresponden a bacterias aeróbicas, pese a haberse encontrado un aerobio estricto y un microaerófilo en el proceso. Estos resultados apoyan el hecho de que la mayoría de la microbiota intestinal de los insectos que se alimentan de la biomasa lignocelulósica está compuesta por aerobios mesófilos y es asimilada a partir del medio en que se desarrollan, no necesariamente incluyendo a microorganismos específicamente endosimbiontes, sino a una abundante cantidad de cepas oportunistas, como lo indican Suárez-Moo et al. (2020).

Adicionalmente, el cultivo en medio líquido probó ser poco eficaz para el aislamiento microbiano, dificultando la diferenciación al microscopio y la obtención de los cultivos puros, a diferencia del cultivo en medio sólido, debido al rápido crecimiento de la población microbiana en las condiciones de cultivo.

\section{CONCLUSIONES}

Se aislaron microorganismos a partir del fluido digestivo de larvas de Rhynchophorus palmarum. Para este propósito se contemplaron medios de cultivo genéricos tanto para hongos como para bacterias, en condiciones de aerobiosis, anaerobiosis y microaerofilia.

Se obtuvo un total de catorce aislados microbianos diferentes, de los cuales ocho corresponden a bacilos 
Gram negativos, dos a bacilos Gram positivos, tres aislados identificados como levaduras y uno como moho.

Con respecto a los requerimientos de oxígeno, se determinó que la mayoría de aislados corresponde a microorganismos aeróbicos, con una escasa presencia de organismos anaeróbicos y microaerófilos.

\section{LITERATURA CITADA}

Capinera, J. L. 2010. Insects and Wildlife. WileyBlackwell. https://doi.org/10.1002/9781444317688

Delalibera, I., Handelsman, J., \& Raffa, K. F. 2005. Contrasts in Cellulolytic Activities of Gut Microorganisms Between the Wood Borer, Saperda vestita (Coleoptera: Cerambycidae), and the Bark Beetles, Ips pini and Dendroctonus frontalis (Coleoptera: Curculionidae). Environmental Entomology, 34(3): 541-547. https://doi.org/10.1603/0046-225X-34.3.541

Delidovich, I., Hausoul, P. J. C., Deng, L., Pfützenreuter, R., Rose, M., \& Palkovits, R. 2016. Alternative Monomers Based on Lignocellulose and Their Use for Polymer Production. In Chemical Reviews. 116(3),1540-1599.

10.1021/acs.chemrev.5b00354

Dillon, R. J., \& Dillon, V. M. 2004. The gut bacteria of insects: nonpathogenic interactions. Annual Review of $\quad$ Entomology, 49(1):71-92. https://doi.org/10.1146/annurev.ento.49.061802.12 3416

Engel, P., \& Moran, N. A. 2013. The gut microbiota of insects-diversity in structure and function. FEMS Microbiology Reviews, 37(5):699-735. https://doi.org/10.1111/1574-6976.12025

Fischer, R., Ostafe, R., \& Twyman, R. M. 2013. Cellulases from insects. En Yellow Biotechnology II (pp. 5164). Springer, Berlin, Heidelberg.

Garofalo, C., Milanović, V., Cardinali, F., Aquilanti, L., Clementi, F., \& Osimani, A. 2019. Current knowledge on the microbiota of edible insects intended for human consumption: A state-of-the-art review. Food Research International 125:108527. https://doi.org/10.1016/j.foodres.2019.108527

Govindarajulu, S. N., Varier, K. M., Jayamurali, D., Liu, W., Chen, J., Manoharan, N., Li, Y., \& Gajendran, B. 2020. Insect gut microbiome and its applications. Recent Advancements in Microbial Diversity, 379395. https://doi.org/10.1016/B978-0-12-821265$3.00016-5$
Jacobsen, R. M., Sverdrup-Thygeson, A., Kauserud, H., \& Birkemoe, T. 2018. Revealing hidden insect-fungus interactions; moderately specialized, modular and anti-nested detritivore networks. Proceedings of the Royal Society B: Biological Sciences, 285(1876). https://doi.org/10.1098/rspb.2017.2833

Jang, S., \& Kikuchi, Y. 2020. Impact of the insect gut microbiota on ecology, evolution, and industry. Current Opinion in Insect Science 41:33-39. https://doi.org/10.1016/j.cois.2020.06.004

Limayem, A., \& Ricke, S. C. 2012. Lignocellulosic biomass for bioethanol production: Current perspectives, potential issues and future prospects. Progress in Energy and Combustion Science. 38(4):449-467.

https://doi.org/10.1016/j.pecs.2012.03.002

Oppert, C., Klingeman, W. E., Willis, J. D., Oppert, B., \& Jurat-Fuentes, J. L. 2010. Prospecting for cellulolytic activity in insect digestive fluids. Comparative Biochemistry and Physiology - B Biochemistry and Molecular Biology, 155(2), 145154. https://doi.org/10.1016/j.cbpb.2009.10.014

Pal, S., y Karmakar, P. 2018. Symbionts associated with insect digestive system and their role in insect nutrition. Journal of Entomology and Zoology Studies, 6(5):421-425.

Ramachandiran, S., Sankaraiyah, K., Kavipriya, J., Vijiyalakshmi, U., \& Sakunthala, C. 2018. Identification and characterization of gut associated bacteria in Epilachna vigintioctopunctata Fab. (Coleoptera : Coccinellidae). Entomon 43(1): 1-6.

Samal, I., \& Kumar Sahu, B. 2020. Symbiosis: It's important nutritional and non-nutritional roles in insects. Journal of Entomology and Zoology Studies, 8(3):1768-1773.

Sancho, D., Gil, M. D. J. A., \& Sánchez, L. D. R. F. 2015. Insectos y alimentación. Larvas de Rhynchophorus palmarum L, un alimento de los pobladores de la Amazonía Ecuatoriana. Entomotropica, 135- 149.

Suárez-Moo, P., Cruz-Rosales, M., Ibarra-Laclette, E., Desgarennes, D., Huerta, C., \& Lamelas, A. 2020. Diversity and composition of the gut microbiota in the developmental stages of the dung beetle Copris incertus Say (Coleoptera, Scarabaeidae). Frontiers in microbiology, 11:1698.

Sufian, M., Al-Ashraf, A. A., \& Zuharah, W. F. 2020. Isolation and identification of the bacterial community associated with the rove beetle, Paederus fuscipes curtis (Coleoptera: Staphylinidae) 
in Penang. Malaysian Applied Biology, 49(1):173-

181.

Szentner, K., Waśkiewicz, A., Kaźmierczak, S., Wojciechowicz, T., Goliński, P., Lewandowska, E., \& Wasielewski, O. 2019. Enzymatic hydrolysis of cellulose using extracts from insects. Carbohydrate Research, 485:107811.

https://doi.org/10.1016/j.carres.2019.107811

Vatanparast, M., Hosseininaveh, V., Ghadamyari, M., \& Minoo Sajjadian, S. 2014. Plant cell wall degrading enzymes, pectinase and cellulase, in the digestive system of the red palm weevil, Rhynchophorus ferrugineus (Coleoptera: Curculionidae). Plant Protection Science, 50(4):190-198. https://doi.org/10.17221/43/2013-PPS 